\section{(6) OPEN ACCESS}

\title{
Update on the safety profile of certolizumab pegol in rheumatoid arthritis: an integrated analysis from clinical trials
}

\author{
V P Bykerk, ${ }^{1}$ J Cush $_{1}{ }^{2} \mathrm{~K}$ Winthrop, ${ }^{3} \mathrm{~L}$ Calabrese, ${ }^{4} \mathrm{O}$ Lortholary, ${ }^{5} \mathrm{M}$ de Longueville, ${ }^{6}$ \\ $\mathrm{R}$ van Vollenhoven, ${ }^{7} \times$ Mariette $^{8}$
}

Handling editor Tore K Kvien

- Additional material is published online only. To view please visit the journal online (http://dx.doi.org/10.1136/ annrheumdis-2013-203660).

For numbered affiliations see end of article.

\section{Correspondence to} Dr Vivian P Bykerk, Hospital for Special Surgery, 535 East 70th Street, New York, NY 10021, USA; BykerkV@HSS.EDU

Received 20 March 2013 Revised 29 August 2013 Accepted 8 September 2013 Published Online First 3 October 2013

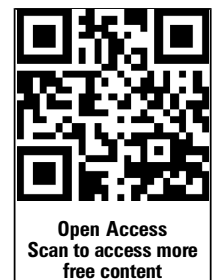

CrossMark

To cite: Bykerk VP, Cush J,

Winthrop K, et al. Ann

Rheum Dis 2015;74:

96-103.
ABSTRACT

Objective To report the long-term safety data of certolizumab pegol (CZP) in rheumatoid arthritis (RA) accumulated as of 30 November 2011.

Design Data from 10 completed randomised controlled trials (RCT) of CZP in RA and several open-label extensions (OLE) were pooled across all doses. Reported adverse events $(A E)$ occurred between the first dose and 84 days after the last dose. All deaths, serious infectious events (SIE) and malignancies were reviewed by external experts, classified according to predefined rules, and validated by an external steering committee. Incidence rates (IR) and event rates (ER) per 100 patient-years (PY) are presented.

Results 4049 RA patients who received CZP were included in the safety pooling; total exposure $9277 \mathrm{PY}$, mean exposure 2.1 years (range $0.04-7.6$ ). SIE, most frequently pneumonia (IR $0.73 / 100 \mathrm{PY}$ ), were the most common serious $A E$, occurring more frequently in CZP compared to placebo-treated patients in RCT (IR 5.61/ 100 PY vs $1.35 / 100$ PY, odds ratio (OR) $4.35,95 \% \mathrm{Cl}$ 0.65 to 29.30). SIE rates were lower in the CZP-treated population including OLE (ER 4.33/100 PY). 44 patients developed tuberculosis (IR 0.47/100 PY), 39 from high endemic regions. 58 deaths occurred in CZP-exposed patients (IR 0.63/100 PY) and 70 developed malignancies excluding non-melanoma skin cancer (IR 0.76/100 PY), including five lymphomas (IR 0.05/ 100 PY).

Conclusions No new or unexpected safety signals associated with CZP emerged in this updated long-term safety analysis. While SIE rates were higher for CZP than for placebo in RCT, the rate decreased with continued exposure to CZP. These rates are consistent with data previously reported for CZP and other tumour necrosis factor inhibitors.

\section{INTRODUCTION}

The widespread use of biological agents has transformed the management of rheumatoid arthritis (RA). Ongoing evaluation of the long-term safety profile of these agents is essential to ensure their effective and appropriate use. Experience to date with biological agents, including tumour necrosis factor (TNF) inhibitors, has highlighted that they are associated with an increased risk of serious bacterial infections, tuberculosis and non-bacterial opportunistic infections, and may be associated with malignancies. ${ }^{1}$ Other potential adverse events (AE) considered important are gastrointestinal perforations, demyelinating disorders and lupuslike syndromes. ${ }^{2} 3$

Certolizumab pegol (CZP) is a pegylated Fc-free TNF inhibitor approved for adult patients with moderate to severe active RA. ${ }^{4}$ In addition to RA, CZP has demonstrated a positive risk benefit in Crohn's disease, psoriasis, psoriatic arthritis and axial spondyloarthritis. ${ }^{6} 78910$ It is estimated close to 47000 patients are receiving CZP worldwide. $^{11}$

To date, the safety of CZP in RA has been evaluated in individual clinical trials (including FAST4WARD, ${ }^{12}$ RAPID $1,{ }^{13}$ RAPID $2,{ }^{14}$ Study 014, ${ }^{15}$ REALISTIC, ${ }^{16}$ CERTAIN $^{17}$ and DOSEFLEX) ${ }^{18}$ and in integrated safety summaries. This paper presents an updated and long-term safety analysis of all CZP-treated patients in RA clinical trials, with CZP exposure of up to 7 years in some patients. The evaluation and review process was led by an external, independent safety steering committee, who identified and defined key AE types, and with expert input performed a manual review of these events.

\section{METHODS}

\section{Data sources and patient populations}

A pooled safety analysis was performed on one open-label, single-dose pharmacokinetic study $(n=16), 10$ randomised controlled trials $(\mathrm{RCT})$ and several open-label extensions (OLE) or other openlabel periods of clinical trials in RA (see supplementary table S1 and figure S1, available online only). Data up to 30 November 2011 were included.

Trials included monotherapy, combination therapy (receiving CZP concomitantly with methotrexate or other disease-modifying antirheumatic drugs) and mixed populations (monotherapy and combination therapy) (see supplementary table S1, available online only). Two formulations of CZP were used, a lyophilised powder for solution or a solution for injection provided in a pre-filled syringe. CZP was administered at a dose of $200 \mathrm{mg}$ once every 2 weeks (Q2W) following a loading dose of $400 \mathrm{mg}$ at weeks 0,2 and 4 (registered dose), CZP $400 \mathrm{mg}$ once every 4 weeks (additional registered dose in USA only) or $400 \mathrm{mg}$ Q2W (dose used in the two pivotal trials (RAPID $1^{13}$ and RAPID $2^{14}$ ) and their OLE).

In RAPID $1^{13}$ and RAPID $2^{14}$ the protocol specified early, mandatory escape to OLE CZP for patients failing to achieve an ACR20 response at weeks 12 and 14. In the RAPID 1 and RAPID 2 
OLE all patients initially received CZP $400 \mathrm{mg}$ Q2W before switching to CZP $200 \mathrm{mg}$ Q2W after at least 6 months.

As the study designs (including patient inclusion and exclusion criteria) and baseline populations of the included trials were largely similar, patient data were pooled without application of corrective factors. Data from two patient populations are presented: (1) the placebo-controlled population (RCT) includes all patients participating in RCT with data presented for placebo and CZP treated patients; (2) the all studies population (RCT + OLE) reports data for any patient exposed to CZP, and includes all patients who withdrew from the RCT and were treated thereafter with CZP. For patients treated with CZP in RCT, events from the RCT are included in both the RCT and RCT + OLE populations.

As well as a general safety update, AE reported here include serious infectious events (SIE), opportunistic infections (OI), tuberculosis, malignancies, major adverse cardiovascular events (MACE), gastrointestinal perforations, demyelinating disorders, anaphylactic disorders and lupus-like syndromes, as well as data on laboratory parameters.

\section{Safety assessments}

$\mathrm{AE}$ and serious adverse events (SAE) were recorded and categorised according to the Medical Dictionary for Regulatory Activities (MedDRA) V.9.0. In some cases, individual symptoms as well as overall diagnoses were each recorded and counted separately, which could lead to overestimation of AE incidence (eg, a patient diagnosed with pharyngitis could also be counted as simultaneously experiencing laryngitis and pyrexia). AE were defined as taking place between the first dose and 84 days after the last dose of the study drug ( 84 days being six times the half-life of CZP). ${ }^{13}$

The definition of SAE was broad, encompassing the regulatory definition of medical occurrences that were life threatening or led to death, hospitalisation, congenital anomalies or birth defects, or resulted in persistent or significant disability. ${ }^{19}$ In addition, all OI, malignancies (excluding some basal-cell carcinomas at the discretion of the investigator) and any medical events deemed important by the investigator were considered SAE. The latter criterion was subject to individual investigator interpretation and no guidance was provided in the study protocols.

MACE included fatal and serious non-fatal myocardial infarction, cerebrovascular events and congestive heart failure, based on MedDRA terms and medical review.

Gastrointestinal perforations were identified using the highlevel term 'gastrointestinal ulcers and perforation, site unspecified' and a manual search to capture other potential cases of gastrointestinal perforation (perforation, abscess, appendicitis, diverticulitis and fistula). A medical review was subsequently performed.

\section{Exposure to CZP}

Total CZP exposure was defined as the time from the first dose to 84 days after the last dose. Exposure to CZP as used in the incidence rate calculation was defined as the time from the first dose until the first occurrence of a particular AE.

Both exposure-adjusted event rates (ER) and incidence rates (IR) per 100 patient-years (PY) are presented in this analysis. When AE occur in individual patients more than once, ER are usually appropriate as all events and the full duration of drug exposure are accounted for (see supplementary figure S2, available online only). When AE typically occur in individual patients only once (eg, in the case of tuberculosis), IR are more appropriate as data are censored after the first occurrence of a particular event in an individual patient.

All statistics were performed using the STAT V.9.1 program.

\section{Centralised external medical review of selected $A E$}

A retrospective central review led by external experts was performed in order to increase the consistency of evaluation of selected AE. The steering committee (VB, JC, RvV, XM) identified $\mathrm{AE}$ of concern to patients treated with biological agents (including SIE, OI, malignancies, demyelinating events, gastrointestinal perforations and death) and oversaw the centralised medical review process. The steering committee manually reviewed the database records for the predefined AE, including the investigator description of each event used by the sponsor for coding the sub committee proposals, in a blinded fashion using predetermined rules, and provided a final diagnosis of each case. The classification rules were developed by consensus with the input of specialist subcommittees of independent clinicians. The subcommittees applied the rules to each case initially and decisions were validated by the steering committee.

The subcommittees for SIE and OI (KW, OL, LC, JC and XM) classified SIE by the regulatory definition of SAE of infection, ${ }^{19}$ with an additional criterion of the need for intravenous antibiotics. A list of OI, including strict diagnosis criteria, was developed and validated by the steering committee. The list of OI and criteria for diagnosis were predominantly derived from validated and published sources such as the Centers for Disease Control and Prevention (CDC), ${ }^{20}$ and were consistent with the RATIO registry (see supplementary table $\mathrm{S} 3$, available online only). ${ }^{21}$

The malignancies committee ( $\mathrm{RvV}$ and an oncologist) categorised malignancies as solid tumours (including melanoma), lymphoma or non-melanoma skin cancer (NMSC).

The committee for deaths (VB and two cardiologists) categorised deaths as primarily due to cardiovascular events, infectious events, malignancies or other causes.

\section{Tuberculosis screening}

In CZP studies before 2007, screening for tuberculosis was conducted according to the respective national guidelines of the recruiting centre (criteria for purified protein derivative (PPD) positivity varied between $\geq 5 \mathrm{~mm}$ and $\geq 20 \mathrm{~mm}$ ). In 2007, protocols were amended mandating that all patients be treated prophylactically for tuberculosis if PPD positivity of $5 \mathrm{~mm}$ or greater was observed at baseline. ${ }^{22} 23$ This amendment was enforced for all patients already on CZP treatment.

\section{Laboratory assessments}

Laboratory assessments including haematology and biochemistry were assessed repeatedly according to protocol in both the RCT and OLE. Markedly abnormal (grade 3 or grade 4) abnormalities were defined in accordance with the rheumatology common toxicity criteria, V.2.0. ${ }^{24}$ For ALT and AST, grade 3 and grade 4 abnormalities were defined as being values three times the upper limit of normal (ULN) or greater; for bilirubin, values of two times ULN or greater; and for creatinine, values 1.8 times ULN or greater.

\section{RESULTS}

\section{Patient population}

The RCT population included 2965 CZP patients and 1137 placebo patients enrolled in 10 RCT in RA (table 1). Overall, 1413 patients were exposed to CZP $400 \mathrm{mg}$ Q2W, twice the registered dose. In CZP-treated patients, mean exposure duration was 152 days and total exposure 1302 PY (table 2). The placebo patients' mean exposure was 110 days and total exposure duration $373 \mathrm{PY}$. 
Table 1 Baseline population characteristics for placebo and CZP-treated patients (all doses) in RCT and RCT+OLE

\begin{tabular}{|c|c|c|c|}
\hline \multirow[b]{2}{*}{$\begin{array}{l}\text { Baseline population } \\
\text { characteristics }\end{array}$} & \multicolumn{2}{|l|}{ RCT } & \multirow{2}{*}{$\begin{array}{l}\text { RCT+OLE } \\
\text { CZP } \\
(n=4049)\end{array}$} \\
\hline & $\begin{array}{l}\text { Placebo } \\
(n=1137)\end{array}$ & $\begin{array}{l}\text { CZP } \\
(n=2965)\end{array}$ & \\
\hline Mean age, years (SD) & $53.1(11.84)$ & $53.3(11.96)$ & $53.2(11.96)$ \\
\hline Female, n (\%) & $905(79.6 \%)$ & $2372(80.0 \%)$ & $3224(79.6 \%)$ \\
\hline Mean disease duration (SD) & $7.95(7.40)$ & $7.57(6.83)$ & $7.68(6.94)$ \\
\hline \multicolumn{4}{|l|}{ Duration of RA in years, $n(\%)$} \\
\hline$\leq 2$ years & $236(20.8 \%)$ & $629(21.2 \%)$ & $848(20.9 \%)$ \\
\hline \multicolumn{4}{|c|}{ Rheumatoid factor at baseline, $\mathrm{n}(\%)$} \\
\hline Negative & $168(14.8 \%)$ & $573(19.3 \%)$ & 707 (17.5\%) \\
\hline Positive & 798 (70.2\%) & $2130(71.8 \%)$ & $2912(71.9 \%)$ \\
\hline Unknown & $171(15.0 \%)$ & $262(8.8 \%)$ & $430(10.6 \%)$ \\
\hline \multicolumn{4}{|l|}{ Geographical region, n (\%) } \\
\hline Western Europe & $278(24.5 \%)$ & $595(20.1 \%)$ & $800(19.8 \%)$ \\
\hline Central Europe & $231(20.3 \%)$ & $636(21.5 \%)$ & $810(20.0 \%)$ \\
\hline Eastern Europe & $102(9.0 \%)$ & $408(13.8 \%)$ & $503(12.4 \%)$ \\
\hline North America & $468(41.2 \%)$ & $1115(37.6 \%)$ & $1673(41.3 \%)$ \\
\hline Rest of the world & $58(5.1 \%)$ & $211(7.1 \%)$ & $263(6.5 \%)$ \\
\hline \multicolumn{4}{|l|}{ Baseline steroid use, n (\%) } \\
\hline Yes & $629(55.3 \%)$ & $1657(55.9 \%)$ & $2229(55.1 \%)$ \\
\hline \multicolumn{4}{|c|}{ Baseline methotrexate use, n (\%) } \\
\hline Yes & $804(70.7 \%)$ & $2272(76.6 \%)$ & $3082(76.1 \%)$ \\
\hline $\begin{array}{l}\text { Previous TNF inhibitor/other } \\
\text { biological agents, } \mathrm{n}(\%)\end{array}$ & $189(16.6 \%)$ & $518(17.5 \%)$ & $744(18.4 \%)$ \\
\hline
\end{tabular}

The RCT+OLE population included 4049 CZP patients participating in RCT, uncontrolled studies $(n=16)$ and OLE (mean exposure duration 782 days (2.1 years); total patient exposure 9277 PY) (table 2). The longest CZP exposure duration was 2759 days (approximately 7.6 years).

\section{Overall safety}

In RCT, the overall IR of AE was 335.86/100 PY for CZP-treated patients compared to $362.27 / 100$ PY for placebotreated patients. In RCT+OLE, IR was $188.83 / 100$ PY. The majority of $\mathrm{AE}$ were of mild to moderate intensity in both populations (table 2). In RCT+OLE, the MedDRA term 'infections and infestations' was the most common type of AE (IR 61.24/ $100 \mathrm{PY})$. The incidence of AE peaked during the first 3 months for CZP and placebo, then decreased over time (figure 1A).

The IR of all SAE was 20.97/100 PY with CZP and 17.01/ 100 PY with placebo in RCT, and 13.96/100 PY in RCT+OLE (table 2). The ER of SAE was 29.49/100 PY with CZP and 21.73/100 PY with placebo in RCT, and 21.31/100 PY in RCT +OLE. ER is usually higher than IR, particularly with longerterm exposure, due to multiple recurrences of the same AE. Pneumonia was the most commonly reported SAE with CZP in both RCT and RCT+OLE (see supplementary table S4, available online only). The incidence of SAE peaked during the first 3 months, then decreased with exposure (figure 1A).

\section{AE leading to treatment discontinuation}

For CZP-treated patients in RCT, the IR of AE leading to treatment withdrawal was 10.24/100 PY (placebo 8.43/100 PY; RCT +OLE CZP 5.85/100 PY). Infections were the most common AE leading to withdrawal in CZP patients in both RCT and RCT+OLE (IR 3.01/100 PY and 1.86/100 PY, respectively).
Across all studies, 73 patients discontinued treatment due to neoplasms (IR 0.79/100 PY).

\section{Deaths}

Among CZP-treated patients in RCT, there were 11 deaths (0.4\%; IR 0.84/100 PY) compared to one death (0.1\%; IR 0.27/ $100 \mathrm{PY})$ in placebo-treated patients. Across the RCT+OLE AE led to death in 58 CZP-treated patients (1.4\%; IR 0.63/100 PY). The rate remained stable over time (figure $1 \mathrm{C}$ ). Death was primarily related to cardiovascular events in 17 patients (IR 0.18 / 100 PY), malignancies in 12 patients (IR 0.13/100 PY) and infections in 13 patients (IR 0.14/100 PY). The populationmatched WHO standardised mortality rate for CZP-treated patients across the RCT+OLE was 0.83 (95\% CI 0.63 to 1.07), using 2008 mortality rates.

\section{Serious infections}

In RCT, SIE occurred with an ER of 6.14 (4.93-7.62)/100 PY in CZP-treated patients, compared to $1.34(0.49-3.28) / 100 \mathrm{PY}$ in the placebo group; (OR 4.81, 95\% CI 0.72 to 31.99 ; table 2) and IR of 5.61/100 PY and 1.35/100 PY for CZP and placebo, respectively (OR 4.35, 95\% CI 0.65 to 29.30). CI related to rare events should be interpreted with caution, due to the asymptotic approximation method used to calculate the CI. In RCT + OLE, SIE occurred in CZP-treated patients with an ER of 4.33/100 PY (IR 3.65/100 PY). IR peaked in the first months of treatment (figure $1 \mathrm{~B}$; see supplementary table $\mathrm{S} 2$, available online only).

In RCT, the most frequent SIE in the CZP-treated group by preferred term included pneumonia (ER 0.77/100 PY), cellulitis (ER 0.38/100 PY), and erysipelas (ER 0.38/100 PY). In RCT +OLE, the most frequent SIE included pneumonia (ER 0.77/ $100 \mathrm{PY}$ ), cellulitis (ER 0.31/100 PY) and urinary tract infection (ER 0.16/100 PY).

\section{Opportunistic infections}

In CZP-treated patients in the RCT population, nine tuberculous events occurred in nine patients (0.69 events/100 PY) compared to none in placebo, while in the RCT+OLE population 44 events occurred in 44 patients ( 0.47 events/100 PY). The majority of tuberculous events (39/44) occurred in central and eastern Europe (IR central Europe 0.58/100 PY; eastern Europe 1.02/100 PY), three events in western Europe (IR 0.23/100 PY) and one event in North America (IR 0.05/100 PY). Eleven of the 44 tuberculosis cases were diagnosed after implementation of the protocol amendment (in January 2008). Among these 11 patients, two cases occurred in trials started after implementation of the protocol amendment. Ten of the 11 patients were PPD negative at baseline (PPD $<5 \mathrm{~mm}$ ), and two patients from central Europe developed active tuberculosis while on prophylactic isoniazid treatment. Across all studies, there were 30 cases of pulmonary (including pleural and mediastinum lymph nodes) tuberculosis (IR 0.32 events/100 PY) and 14 cases of extrapulmonary or disseminated tuberculosis (table 4). No nontuberculous mycobacterial infections were identified.

Five other OI occurred in CZP-treated patients in the RCT population (ER 0.38/100 PY), while 21 other OI occurred in the RCT+OLE population (ER 0.23/100 PY) (table 2). The most common non-tuberculous OI were oesophageal candidiasis and bronchopulmonary aspergillosis (table 3 ). No OI were reported in the placebo group. The rate of OI did not increase with prolonged exposure to CZP (figure 1B). No cases of progressive multifocal leukoencephalopathy were reported. 
Table 2 Adverse events and serious adverse events reported for CZP-treated patients (all doses) in the placebo-controlled population (RCT) and all studies (RCT+OLE) population

\begin{tabular}{|c|c|c|c|c|c|c|c|c|c|c|c|c|}
\hline & \multicolumn{8}{|c|}{ RCT } & \\
\hline & \multicolumn{3}{|c|}{$\begin{array}{l}\text { Placebo } \\
\text { ( } \mathrm{n}=1137)\end{array}$} & \multicolumn{5}{|c|}{$\begin{array}{l}\text { All CZP doses } \\
\quad(n=2965)\end{array}$} & \multicolumn{4}{|c|}{$\begin{array}{l}\text { All CZP doses } \\
\qquad(n=4049)\end{array}$} \\
\hline Total exposure (PY) & \multicolumn{3}{|c|}{373} & \multicolumn{5}{|c|}{1302} & \multicolumn{4}{|c|}{9277} \\
\hline Mean exposure (days) & \multirow{2}{*}{\multicolumn{3}{|c|}{$\begin{array}{l}110 \\
111\end{array}$}} & \multirow{2}{*}{\multicolumn{5}{|c|}{$\begin{array}{l}152 \\
112\end{array}$}} & & 782 & & \\
\hline \multirow[t]{2}{*}{ Median exposure (days) } & & & & & & & & & \multicolumn{4}{|c|}{267} \\
\hline & IR/100 PY (95\% CI) & ER/100 PY $(95 \% \mathrm{Cl})$ & N pts & $\%$ pts & IR/100 PY (95\% CI) & ER/100 PY $(95 \% \mathrm{Cl})$ & $\mathrm{N}$ pts & $\%$ pts & IR/100 PY (95\% Cl) & ER/100 PY (95\% Cl) & N pts & $\%$ pts \\
\hline AE & 362.27 (336.16 to 389.86$)$ & $589.10(\mathrm{~N} / \mathrm{A})$ & 713 & 62.7 & 335.86 (321.47 to 350.72$)$ & $568.30(\mathrm{~N} / \mathrm{A})$ & 2048 & 69.1 & 188.83 (182.68 to 195.14$)$ & $328.93(\mathrm{~N} / \mathrm{A})$ & 3561 & 87.9 \\
\hline Mild & 217.37 (199.25 to 236.69 ) & $342.30(\mathrm{~N} / \mathrm{A})$ & 530 & 46.6 & 218.81 (208.28 to 229.73) & $352.35(\mathrm{~N} / \mathrm{A})$ & 1620 & 54.6 & 109.88 (106.02 to 113.84$)$ & $191.84(\mathrm{~N} / \mathrm{A})$ & 3059 & 75.5 \\
\hline Moderate & 134.97 (121.81 to 149.17$)$ & $212.73(\mathrm{~N} / \mathrm{A})$ & 384 & 33.8 & 115.85 (109.17 to 122.84$)$ & 186.70 (N/A) & 1120 & 37.8 & 61.00 (58.65 to 63.42 ) & 119.31 (N/A) & 2546 & 62.9 \\
\hline Severe & 26.24 (21.18 to 32.14$)$ & 34.07 (29.31 to 39.16$)$ & 93 & 8.2 & 20.50 (18.07 to 23.17$)$ & 29.26 (26.82 to 31.83$)$ & 256 & 8.6 & 10.77 (10.07 to 11.52$)$ & 17.77 (17.00 to 18.57$)$ & 867 & 21.4 \\
\hline AE leading to death & $0.27(0.01$ to 1.49$)$ & 0.27 (0.01 to 1.72$)$ & 1 & 0.1 & $0.84(0.42$ to 1.51$)$ & 1.08 (0.61 to 1.84$)$ & 11 & 0.4 & $0.63(0.47$ to 0.81$)$ & 0.67 (0.52 to 0.86$)$ & 58 & 1.4 \\
\hline SAE & 17.01 (13.01 to 21.85$)$ & 21.73 (17.72 to 26.33$)$ & 61 & 5.4 & 20.97 (18.50 to 23.68$)$ & 29.49 (27.04 to 32.06$)$ & 260 & 8.8 & 13.96 (13.14 to 14.83$)$ & 21.31 (20.48 to 22.16 ) & 1063 & 26.3 \\
\hline SIE & $1.35(0.44$ to 3.14$)$ & 1.34 (0.49 to 3.28$)$ & 5 & 0.4 & 5.61 (4.39 to 7.06$)$ & $6.14(4.93$ to 7.62$)$ & 72 & 2.4 & 3.65 (3.26 to 4.07$)$ & 4.33 (3.93 to 4.77$)$ & 324 & 8.0 \\
\hline $\begin{array}{l}\text { All malignancies excluding } \\
\text { NMSC }\end{array}$ & 0.81 (0.17 to 2.36$)$ & 1.34 (0.49 to 3.28$)$ & 3 & 0.3 & 0.77 (0.37 to 1.41$)$ & 0.84 (0.44 to 1.56$)$ & 10 & 0.3 & 0.76 (0.59 to 0.96$)$ & 0.78 (0.61 to 0.98$)$ & 70 & 1.7 \\
\hline Ol excluding tuberculosis & 0 & 0 & 0 & 0 & 0.31 (0.08 to 0.79$)$ & 0.38 (0.14 to 0.95$)$ & 4 & 0.1 & $0.19(0.12$ to 0.31$)$ & $0.23(0.14$ to 0.35$)$ & 18 & 0.4 \\
\hline Tuberculous infections & 0 & 0 & 0 & 0 & 0.69 (0.32 to 1.31$)$ & 0.69 (0.34 to 1.36$)$ & 9 & 0.3 & $0.47(0.34$ to 0.64$)$ & $0.47(0.35$ to 0.64$)$ & 44 & 1.1 \\
\hline MACE & 0.54 (0.07 to 1.94$)$ & 0.54 (0.09 to 2.14) & 2 & 0.2 & 1.08 (0.59 to 1.81$)$ & 1.15 (0.67 to 1.94$)$ & 14 & 0.5 & $0.71(0.55$ to 0.91$)$ & $0.82(0.65$ to 1.03$)$ & 66 & 1.6 \\
\hline
\end{tabular}

*Treatment-emergent adverse events of oesophageal candidiasis were included as $0 \mathrm{l}$

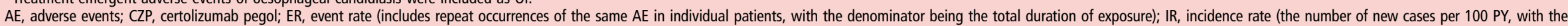
denominator being the exposure duration up to the first occurrence of a particular AE): MACE, major adverse cardiovascular event; N/A, not available, due to number of events being greater than the number of time units; NMSC, non-melanoma skin

cancer; OI, opportunistic infection; OLE, open-label extension; pts, patients; PY, patient-years; RCT, randomised controlled trial; SAE, serious adverse event; SIE; serious infectious event. 
Figure 1 Incidence rates over time in all patients receiving CZP (all doses) in RCT+OLE and placebo populations.

(A) Treatment-emergent and serious adverse events. (B) Serious infections, opportunistic infections, and tuberculosis. (C) MACE, malignancy, and death. CZP, certolizumab pegol all doses; IR, incidence rate; MACE, major adverse cardiovascular event; OI, opportunistic infections excluding tuberculosis; OLE, open-label extension; PBO, placebo; RCT, randomised controlled trial; $\mathrm{SAE}$, serious adverse event; $\mathrm{SIE}$, serious infectious event; TB, tuberculosis; TEAE, treatment-emergent adverse event. IR are calculated over set exposure periods and reported at the average exposure time within each period (eg, 4.5 months for 3-6 month exposure). Note: Rates of MACE, malignancy and death in the placebo group are very similar at month 4.5 and 0 at month 9 and therefore lines between these time points are superimposed. Note: $Y$ axis of panels $A$ and $B$ is not continuous.
A

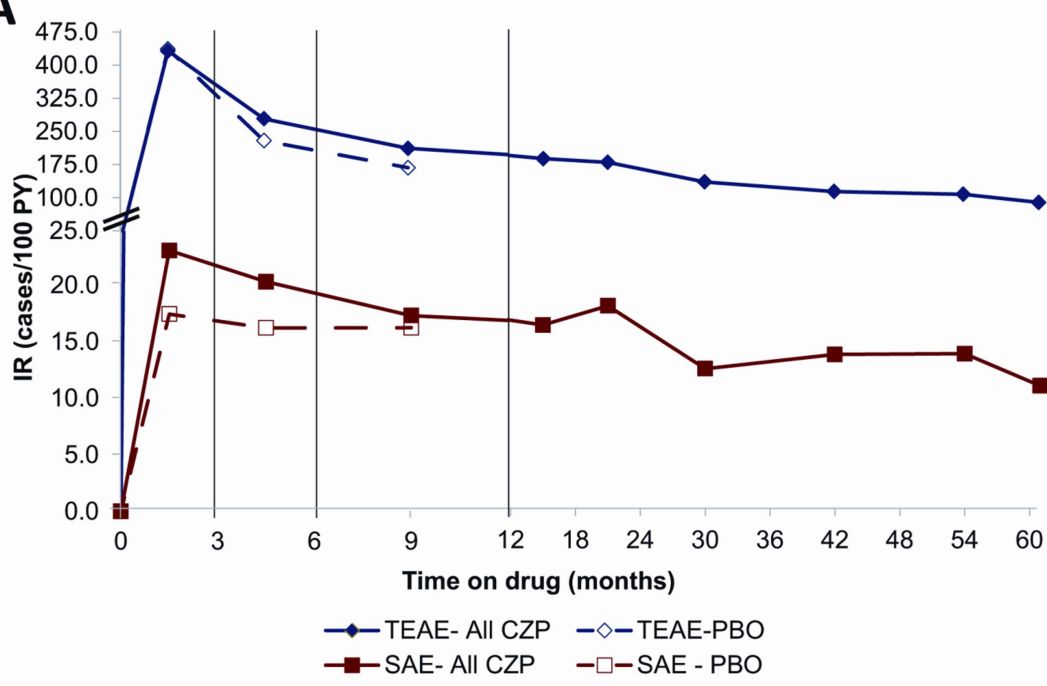

B
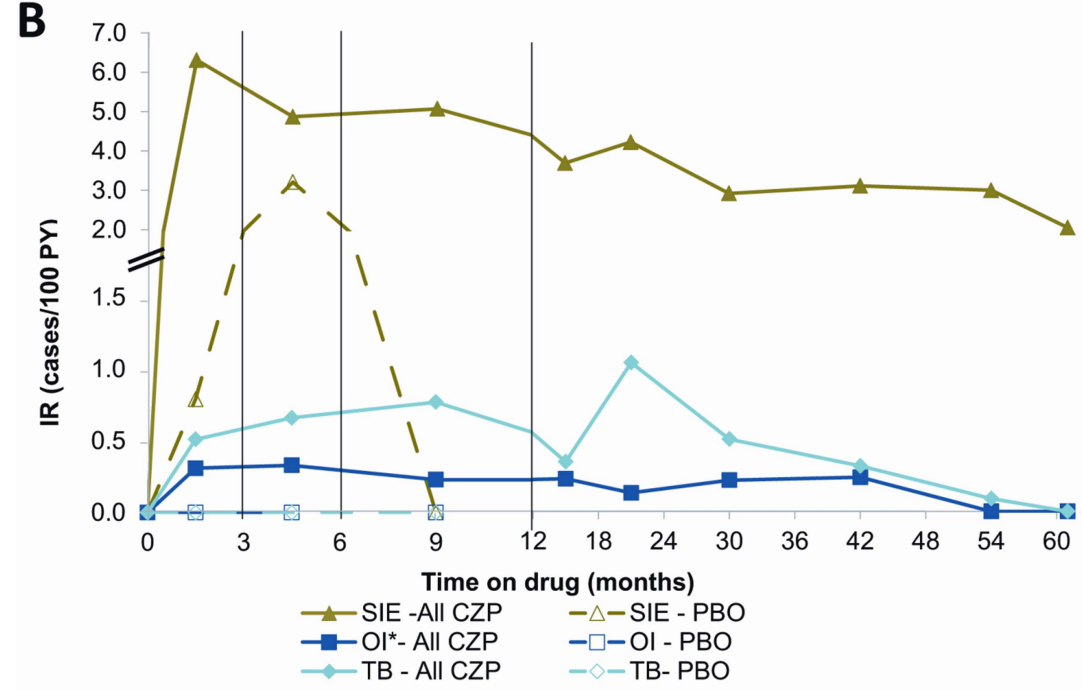

C

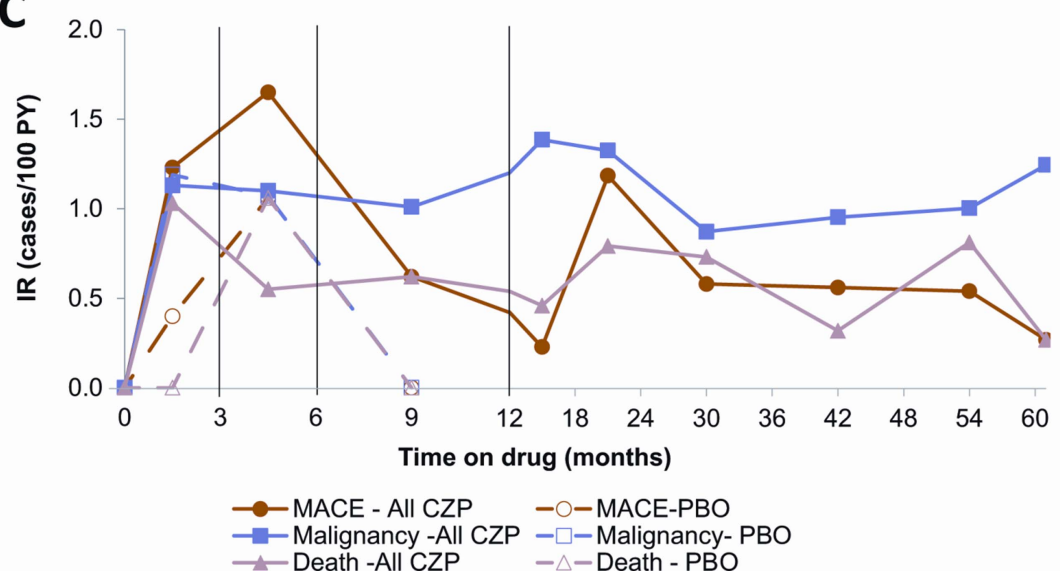

\section{Malignancies}

In patients treated with CZP, 67 solid malignancies were reported in 66 patients, five patients developed lymphoma, and 25 patients developed NMSC (34 events) across all studies (table 4). In the RCT+OLE population, IR were 0.71/100 PY and $0.27 / 100$ PY for solid tumours and NMSC, respectively, and $0.05 / 100$ PY for lymphoma. Breast cancer was the most common solid tumour in women, with 11 events (IR 0.12/ $100 \mathrm{PY}$ ) occurring in CZP-treated patients in the RCT+OLE population. The five lymphoma cases included one each of extranodal marginal zone B-cell lymphoma, diffuse large B-cell lymphoma, Hodgkin's disease, mycoses fungoides and non-Hodgkin's lymphoma. IR of malignancy remained stable in the RCT+OLE population over time (figure 1C, table 4). There were no cases of hepatosplenic T-cell lymphoma.

As the majority of the exposed population was from outside the USA, it was deemed appropriate to calculate standardised IR using malignancy rates in the WHO general population using 
Table 3 Opportunistic infections (including tuberculosis) for CZP-treated patients (all doses) in RCT and RCT+OLE

\begin{tabular}{|c|c|c|c|c|}
\hline & \multicolumn{2}{|c|}{$\begin{array}{l}\text { RCT } \\
\text { CZP } \\
(n=2965) \\
\end{array}$} & \multicolumn{2}{|c|}{$\begin{array}{l}\text { RCT+OLE } \\
\text { CZP } \\
(n=4049) \\
\end{array}$} \\
\hline & $\begin{array}{l}\text { ER/100 } \\
\text { PY }\end{array}$ & $\begin{array}{l}\text { No of } \\
\text { events }\end{array}$ & $\begin{array}{l}\text { ER/100 } \\
\text { PY }\end{array}$ & $\begin{array}{l}\text { No of } \\
\text { events }\end{array}$ \\
\hline Bronchopulmonary aspergillosis & 0.23 & 3 & 0.03 & 3 \\
\hline Oesophageal or oral candidiasis & 0.15 & 2 & 0.08 & 7 \\
\hline $\begin{array}{l}\text { Fungal oesophagitis or gastrointestinal } \\
\text { infection }\end{array}$ & 0 & 0 & 0.02 & 2 \\
\hline Herpes zoster disseminated & 0 & 0 & 0.03 & 3 \\
\hline Histoplasmosis disseminated & 0 & 0 & 0.02 & 2 \\
\hline Nocardiosis & 0 & 0 & 0.01 & 1 \\
\hline Pneumocystis jiroveci pneumonia & 0 & 0 & 0.01 & 1 \\
\hline Soft tissue salmonella & 0 & 0 & 0.01 & 1 \\
\hline Gastroenteritis salmonella & 0 & 0 & 0.01 & 1 \\
\hline Tuberculosis infections & 0.69 & 9 & 0.47 & 44 \\
\hline Pulmonary tuberculosis* & 0.38 & 5 & 0.32 & 30 \\
\hline $\begin{array}{l}\text { Extrapulmonary or disseminated } \\
\text { tuberculosis* }\end{array}$ & 0.31 & 4 & 0.15 & 14 \\
\hline \multicolumn{5}{|c|}{$\begin{array}{l}\text { No OI occurred in patients receiving placebo. } \\
\text { *Pulmonary tuberculosis includes pleural and mediastinum lymph node tuberculosis. } \\
\text { The other } 14 \text { tuberculous events were either extrapulmonary only or disseminated } \\
\text { tuberculosis. Of the } 44 \text { tuberculous events, } 11 \text { events were diagnosed after } 1 \text { January } 2008 . \\
\text { CZP, certolizumab pegol; ER, event rate; OI, opportunistic infection; OLE, open-label } \\
\text { extension; PY, patient-years; RCT, randomised controlled trial. }\end{array}$} \\
\hline
\end{tabular}

the GLOBOCAN database. Using GLOBOCAN, the age and gender-matched standardised IR for all malignancies excluding NMSC in all CZP-treated patients was 1.27 (95\% CI 0.99 to 1.61 ) and 1.06 (0.82 to 1.33) using the US population-matched Surveillance Epidemiology and End Results (SEER) database. For lymphoma only, the standardised IR for CZP-treated patients was 2.72 (95\% CI 0.88 to 6.34) using GLOBOCAN, and 1.81 (95\% CI 0.59 to 4.23$)$ using the SEER database.

\section{Other events of interest}

A total of 76 MACE events were identified (ER 0.82/100 PY) in the RCT+OLE population. The rate of MACE events peaked in the first 6 months of therapy (figure 1C).

In CZP-treated patients in the RCT+OLE population, no cases of multiple sclerosis, optic neuritis or other demyelinating disorders were reported.

In the RCT or RCT + OLE populations, no cases of anaphylactic shock possibly related to CZP were reported. Two mild immuno-allergic reactions were reported. One was reported by the primary investigator as being related to diclofenac, and occurred 115 days after the administration of the first CZP dose and 3 days after the most recent CZP dose. The second, related by the primary investigator to a bee sting, occurred more than 4 years after the first dose of CZP. In both cases, $\mathrm{CZP}$ injections were continued without any recurrences of the reaction.

In CZP-treated patients in RCT, possible mild to moderate lupus-like syndrome, as defined by the investigator with no specific protocol guidance provided, was reported in three patients (ER 0.38/100 PY). No events were reported in placebo patients. In RCT+OLE, seven patients reported possible cases of mild to moderate lupus-like syndrome (ER 0.10/100 PY).

Six gastrointestinal perforations with CZP in RCT+OLE (ER $0.07 / 100 \mathrm{PY}$ ) have been reported in detail elsewhere. ${ }^{25}$

\section{Laboratory parameters}

Baseline data, change from baseline, shift tables and by-subject review of possible clinically relevant laboratory abnormalities for creatinine and liver parameters (bilirubin, ALT and AST) did not identify any clinically relevant effect of CZP (see supplementary table S5, available online only). Grade 3 abnormalities were generally infrequent and occurred similarly between groups within RCT. Changes in lipid profile were not measured in these studies.

Table 4 Malignancies reported for CZP-treated patients (all doses) in RCT+OLE, by type and time of occurrence

\begin{tabular}{|c|c|c|c|c|c|c|}
\hline \multirow[b]{2}{*}{ Cancer } & \multicolumn{2}{|l|}{$\begin{array}{l}\text { RCT } \\
\text { Placebo } \\
\text { ( } n=1137)\end{array}$} & \multicolumn{2}{|l|}{$\begin{array}{l}\text { RCT } \\
\text { CZP } \\
(n=2965) \\
\end{array}$} & \multicolumn{2}{|l|}{$\begin{array}{l}\text { RCT+OLE } \\
\text { CZP } \\
(n=4049)\end{array}$} \\
\hline & IR/100 PY (95\% Cl) & No of events & IR/100 PY (95\% Cl) & No of events & IR/100 PY (95\% CI) & No of events \\
\hline All malignancies excluding NMSC & 0.81 (0.17 to 2.36$)$ & 5 & $0.77(0.37$ to 1.41$)$ & 11 & $0.76(0.59$ to 0.96$)$ & 72 \\
\hline Solid tumour* & 0.81 (0.17 to 2.36 ) & 5 & $0.69(0.32$ to 1.31$)$ & 10 & 0.71 (0.55 to 0.91 ) & 67 \\
\hline NMSC & 0.27 (0.01 to 1.49$)$ & 1 & 0.23 (0.05 to 0.67 ) & 6 & $0.27(0.18$ to 0.40$)$ & 34 \\
\hline Lymphoma & 0 & 0 & $0.08(0.00$ to 0.43$)$ & 1 & $0.05(0.02$ to 0.13$)$ & 5 \\
\hline
\end{tabular}

\section{All malignancies including NMSC}

\begin{tabular}{llll}
\hline Time of occurrence (months on CZP) & No of patients in safety pooling & IR/100 PY (95\% CI) & No of events during time period \\
\hline $0-<3$ & 4049 & $1.13(0.57$ to 2.03$)$ & 12 \\
$\geq 3-<6$ & 3886 & $1.10(0.53$ to 2.03$)$ & 11 \\
$\geq 6-<12$ & 3449 & $1.01(0.54$ to 1.72$)$ & 18 \\
$\geq 12-<18$ & 1960 & $1.38(0.71$ to 2.42$)$ & 12 \\
$\geq 18-<24$ & 1655 & $1.32(0.63$ to 2.42$)$ & 11 \\
$\geq 24-<36$ & 1466 & $0.87(0.45$ to 1.53$)$ & 12 \\
$\geq 36-<48$ & 1334 & $0.95(0.49$ to 1.67$)$ & 13 \\
$\geq 48-<60$ & 1219 & $1.00(0.50$ to 1.79$)$ & 11 \\
$\geq 60$ & 941 & $1.24(0.57$ to 2.35$)$ & 10 \\
\hline *Excluding non-melanoma skin cancer (NMSC). & &
\end{tabular}




\section{DISCUSSION}

The safety of CZP in RA has been comprehensively evaluated based on 4049 CZP-treated RA patients, collectively comprising 9277 PY, with individual patient exposures of up to 7.6 years.

As previously reported, ${ }^{26} \mathrm{AE}$ and SAE peaked during the first 3-6 months of both CZP and placebo treatment. These rates decreased after the initial 6 months of therapy. This may be due to a 'survival bias' whereby patients who are intolerant to the drug do not continue into the OLE. The overall rate of AE reported is, therefore, influenced by the CZP exposure period over which the rate is calculated.

Patients with RA are at an increased risk of infection compared to the general population. ${ }^{27}$ Furthermore, there is an increased risk of SIE associated with biological agents, predominantly during the first months of treatment, and which some studies have identified with TNF inhibitors particularly. ${ }^{28} 2930313233$ In line with this, and the recent meta-analysis of SIE performed by the Cochrane Collaboration, ${ }^{34}$ there was an initial increase in the rate of SIE in patients receiving CZP compared to placebo patients, and infections were the most common SAE. Mandatory early withdrawal of patients without an ACR20 response at weeks 12 and 14 in RAPID 1 and RAPID 2 studies resulted in higher withdrawal rates for placebo compared to CZP-treated patients, resulting in a fourfold increased total exposure of patients to CZP versus placebo. Therefore, comparisons between these groups in RCT should be interpreted with caution. ${ }^{35}$ Moreover, patients in these two studies received higher than indicated doses of CZP, but the effect of dose was not analysed in this integrated safety update.

As in most OLE, the rate of SIE did not increase with prolonged exposure to $\mathrm{CZP}$ and is in line with that reported in the literature for other TNF inhibitors (ER range from 2.6/100 PY to 6.4/100 PY). ${ }^{26323336}$ Caution is necessary, however, when making indirect comparisons between biologics or when reviewing meta-analyses, as study populations differ across trials in terms of the inclusion and exclusion criteria, risk factors, geographical regions and standards of care. Furthermore, the definition of SIE differs between studies and it is not always transparent if IR or ER are being reported. ER are particularly relevant for long-term extension studies, when more than one SIE can be reported in an individual patient. Treatment with any biologic, including CZP, should not be started in a patient with an active infection and patients should be continuously monitored for the development of infections.

Tuberculosis rates in RCT and RCT+OLE (IR 0.69/100 PY and $0.47 / 100$ PY, respectively) are in line with those reported for other monoclonal TNF inhibiting antibodies, including adalimumab (reported as being 0.50/100 PY in the ReAcT study, ${ }^{37}$ and $0.29 / 100 \mathrm{PY}$ in a recent analysis of long-term safety data from clinical trials in RA). ${ }^{38}$ Cases of tuberculosis, which were predominantly reported in central and eastern Europe, fell significantly after the introduction of standardised tuberculosis screening (PPD $\geq 5 \mathrm{~mm}$ ) across CZP clinical trials in 2007 . These data highlight the fact that routine tuberculosis screening applying strict PPD criteria is a critical component of management for patients being considered for TNF inhibitor therapy, and that clinical vigilance during long-term treatment is essential. No non-tuberculous mycobacterial infections have been reported with CZP but the included trial populations had relatively few comorbidities, such as diabetes mellitus. No cases of multifocal leukoencephalopathy have been reported, and the frequency of non-tuberculous OI with CZP appears to be low.

There is no signal showing an increased risk of malignancy with CZP in general and over time compared to the general population, with no cases of hepatosplenic T-cell lymphoma reported. The incidence rate of all malignancies excluding NMSC with CZP in RCT+OLE $(0.76 / 100 \mathrm{PY})$ is similar to data from a US observational database $(1.30 / 100 \mathrm{PY}) .{ }^{39}$ The rate of lymphoma cases reported with CZP (IR 0.05/100 PY) is also in line with that reported in the Swedish Biologics Register for patients treated with TNF inhibitor therapy (0.096 events/100 PY) and RA patients naive to TNF inhibitor therapy (0.092 events/100 PY). ${ }^{40}$

$\mathrm{RA}$ is associated with an increased risk of cardiovascular disease and cardiovascular deaths. ${ }^{41}$ Some studies have suggested that the use of TNF inhibitors may reduce the risk of cardiovascular events in RA patients. ${ }^{41-44}$ The risk of MACE with CZP did not increase with increased exposure duration.

Five out of six patients who developed gastrointestinal perforations while receiving CZP had previous risk factors. The event rate of gastrointestinal perforations observed with CZP is within the range reported by Curtis et $a l^{45}$ for TNF inhibitor users concomitantly exposed to oral corticosteroids.

Evidence has recently emerged indicating that many biological agents may be associated with an increased risk of demyelinating disease. $^{46} 47$ Lupus-like reactions and anaphylactic reactions were rare events with the use of CZP. A detailed search of the safety database, using validated terms such as multiple sclerosis, optic neuritis and other demyelinating conditions, did not identify any demyelinating events in patients receiving CZP in RA clinical trials to date. Lupus-like reactions and anaphylactic reactions were also rare events with the use of CZP.

Similarities in recruited patients and study design in the clinical trials allowed pooling of data and a more comprehensive safety assessment. The external medical review allowed an independent (although retrospective) review of data reported by investigators. The limitations of the dataset include the fact that clinical trials are subject to strict inclusion and exclusion criteria, with rigorous patient monitoring throughout treatment; therefore this patient population likely have fewer comorbidities than those seen in daily clinical practice. Differential reporting of $\mathrm{AE}$, particularly $\mathrm{OI}$ also highlights the need for clear instructions and definitions of $\mathrm{AE}$ for investigators for optimal data collection. There is a need for the ongoing monitoring of the safety profile of CZP within the clinical practice environment.

No new or unexpected safety signals have emerged in this longterm safety analysis of RA clinical trials, and the data are consistent with those reported in the post-marketing use of CZP. There were no increases in the event rate of AE, SAE or SIE with prolonged exposure. This updated longer-term safety analysis for CZP in RA is in line with the $\mathrm{AE}$ profile previously reported and with other biologics, including TNF inhibitors.

\section{Author affiliations \\ ${ }^{1}$ Hospital for Special Surgery, New York, New York, USA \\ ${ }^{2}$ Baylor Research Institute and Baylor University Medical Center, Dallas, Texas, USA \\ ${ }^{3}$ Oregan Health and Science University, Portland, Oregon, USA \\ ${ }^{4}$ Department of Rheumatologic and Immunologic Disease, Cleveland Clinic, Cleveland, Ohio, USA \\ ${ }^{5}$ HU Imagine, Université Paris Descartes, Hôpital Necker Enfants malades, Paris, France \\ ${ }^{6}$ UCB Pharma SA, Brussels, Belgium \\ ${ }^{7}$ Department of Rheumatology, Karolinska Institute, Stockholm, Sweden \\ ${ }^{8}$ Université Paris-Sud, AP-HP, Hôpitaux universitaires Paris-Sud, Paris, France}

Acknowledgements The authors would like to thank Naveed Sattar, cardiologist, and colleagues (Glasgow) and Anders Österborg, oncologist (Stockholm), for their contribution to the external medical review; Marine Champsaur, UCB Pharma, Brussels, Belgium for publication coordination; and Costello Medical Consulting, UK, for writing and editorial assistance.

Funding The CZP safety analysis was funded by UCB Pharma.

Competing interests $\mathrm{VB}, \mathrm{KW}, \mathrm{LC}$ and $\mathrm{OL}$ have no conflicts to declare. JC has received research grants from Pfizer, Celgene, CORRONA, Amgen, NIH, Novartis, 
and UCB Pharma. MdL is an employee of UCB Pharma. RvV has received research grants from Abbott, BMS, GSK, MSD, Pfizer, Roche, UCB Pharma, consultant fees from Abbott, BMS, GSK, MSD, Pfizer, Roche, UCB Pharma. XM has received consulting fees from Bristol-Myers Squibb, GSK, Pfizer, Roche, UCB Pharma and research grants from Pfizer, Roche.

Ethics approval This study received ethics approval from the various participating organisations.

Provenance and peer review Not commissioned; externally peer reviewed.

Open Access This is an Open Access article distributed in accordance with the Creative Commons Attribution Non Commercial (CC BY-NC 3.0) license, which permits others to distribute, remix, adapt, build upon this work non-commercially, and license their derivative works on different terms, provided the original work is properly cited and the use is non-commercial. See: http://creativecommons.org/ licenses/by-nc/3.0/

\section{REFERENCES}

1 Woodrick RS, Ruderman EM. Safety of biologic therapy in rheumatoid arthritis. Nat Rev Rheumatol 2011;7:639-52.

2 Burmester GR, Mease P, Dijkmans BA, et al. Adalimumab safety and mortality rates from global clinical trials of six immune-mediated inflammatory diseases. Ann Rheum Dis 2009;68:1863-9.

3 Schiff $\mathrm{M}$, Kremer J, Jahreis $\mathrm{A}$, et al. Integrated safety in tocilizumab clinical trials. Arthritis Res Ther 2011;13:R141. http://arthritis-research.com/content/13/5/R141

4 European Medicines Agency. Annex 1: Summary of product characteristics (Cimzia). 2013. http://www.ema.europa.eu/ema/ (accessed Aug 2013).

5 UCB Pharma. CIMZIA prescribing information. 2012.

6 Mease P, Fleischmann R, Deodhar AA, et al. Effect of certolizumab pegol on signs and symptoms in patients with psoriatic arthritis: 24-week results of a Phase 3 double-blind randomised placebo-controlled study (RAPID-PsA). Ann Rheum Dis 2014;73:48-55.

7 van der Heijde D, Fleischmann R, Wollenhaupt J, et al. Effect of different imputation approaches on the evaluation of radiographic progression in patients with psoriatic arthritis: results of the RAPID-PsA 24-week phase III double-blind randomised placebo-controlled study of certolizumab pegol Ann Rheum Dis 2014; 73:233-7.

8 Reich K, Ortonne JP, Gottlieb AB, et al. Successful treatment of moderate to severe plaque psoriasis with the PEGylated Fab' certolizumab pegol: results of a phase II randomized, placebo-controlled trial with a re-treatment extension. $\mathrm{Br}$ J Dermatol 2012;167:180-90.

9 Schreiber S. Certolizumab pegol for the treatment of Crohn's disease. Ther Adv Gastroenterol 2011:4:375-89.

10 Landewé R, Braun J, Deodhar AA, et al. Efficacy of certolizumab pegol on signs and symptoms of axial spondyloarthritis including ankylosing spondylitis: 24 week results of a double-blind randomized placebo-controlled phase 3 study. Ann Rheum Dis 2014;73:39-47.

11 UCB Pharma. Data on file regarding the number of patients receiving CZP worldwide. August 2012.

12 Fleischmann R, Vencovsky J, van Vollenhoven RF, et al. Efficacy and safety of certolizumab pegol monotherapy every 4 weeks in patients with rheumatoid arthritis failing previous disease-modifying antirheumatic therapy: the FAST4WARD study. Ann Rheum Dis 2009;68:805.

13 Keystone E, van der Heijde D, Mason D Jr, et al. Certolizumab pegol plus methotrexate is significantly more effective than placebo plus methotrexate in active rheumatoid arthritis: Findings of a fifty two-week, phase III, multicenter, randomized, double blind, placebo controlled, parallel group study. Arthritis Rheum 2008;58:3319-29.

14 Smolen J, Landewé RB, Mease $\mathrm{P}$, et al. Efficacy and safety of certolizumab pegol plus methotrexate in active rheumatoid arthritis: the RAPID 2 study. A randomised controlled trial. Ann Rheum Dis 2009;68:797.

15 Choy E, McKenna F, Vencovsky J, et al. Certolizumab pegol plus MTX administered every 4 weeks is effective in patients with RA who are partial responders to MTX. Rheumatology (Oxford) 2012;51:1226-34.

16 Weinblatt $M$, Fleischmann $R$, Huizinga $T$, et al. Efficacy and safety of certolizumab pegol in a broad population of patients with active rheumatoid arthritis: results from the phase IIIb REALISTIC study. Rheumatology (Oxford) 2012;51:2204-14.

17 Smolen J, Emery P, Ferraccioli GF, et al. Efficacy and safety of certolizumab pegol after incomplete response to disease-modifying anti-rheumatic drugs in rheumatoid arthritis patients with low moderate disease activity: results from CERTAIN, a phase IIIb study [abstract]. Ann Rheum Dis 2011;70(Suppl. 3):259.

18 Furst DE, Shaikh SA, Greenwald M, et al. Evaluation of two dosing regimens of certolizumab pegol for maintenance of clinical response in patients with active rheumatoid arthritis: primary results from Doseflex, a phase IIIb study [abstract]. Ann Rheum Dis 2012;71(Suppl. 3):513.

19 Food and Drug Administration. Reporting Serious Problems to the FDA: What is a Serious Adverse Event? 2012. http://www.fda.gov/safety/medwatch/howtoreport/ ucm053087.htm
20 Centers for Disease Control and Prevention. Nationally Notifiable Infectious Conditions. 2012. http://wwwn.cdc.gov/NNDSS/script/ConditionList.aspx? Type $=0 \& \mathrm{Yr}=2013$

21 Salmon-Ceron D, Tubach F, Lortholary 0, et al. Drug-specific risk of non-tuberculosis opportunistic infections in patients receiving anti-TNF therapy reported to the 3-year prospective French RATIO registry. Ann Rheum Dis 2011;70:616.

22 WHO. Global tuberculosis control. Geneva: World Health Organization, 2010.

23 Centers for Disease Control and Prevention: Division of Tuberculosis Elimination. Fact Sheet: TB Elimination-Tuberculin Skin Testing. 2011. http://www.cdc.gov/tb/ publications/factsheets/testing/skintesting.pdf (accessed 14 Jan 2013).

24 Woodworth T, Furst DE, Alten R, et al. Standardizing assessment and reporting of adverse effects in rheumatology clinical trials II: the Rheumatology Common Toxicity Criteria v.2.0. J Rheumatol 2007:34:1401-14.

25 Fleischmann R, Rubbert-Roth A, Combe B, et al. Gastrointestinal perforations with certolizumab pegol [abstract]. Ann Rheum Dis 2012;71(Suppl. 3):370.

26 Galloway JB, Hyrich KL, Mercer LK, et al. Anti-TNF therapy is associated with an increased risk of serious infections in patients with rheumatoid arthritis especially in the first 6 months of treatment: updated results from the British Society for Rheumatology Biologics Register with special emphasis on risks in the elderly. Rheumatology 2011;50:124-31.

27 Doran MF, Crowson CS, Pond GR, et al. Frequency of infection in patients with rheumatoid arthritis compared with controls: a population-based study. Arthritis Rheum 2002:46:2287-93.

28 European Medicines Agency. Annex 1: Summary of product characteristics (Enbrel). 2013. http://www.ema.europa.eu/ema/ (accessed Aug 2013).

29 European Medicines Agency. Annex 1: Summary of product characteristics (Remicade). 2012. http://www.ema.europa.eu/ema/ (accessed Aug 2013).

30 European Medicines Agency. Annex 1: Summary of product characteristics (Humira). 2013. http://www.ema.europa.eu/ema/ (accessed Aug 2013).

31 European Medicines Agency. Annex 1: Summary of product characteristics (Simponi). 2013. http://www.ema.europa.eu/ema/ (accessed Aug 2013).

32 Kievit W, Creemers MCW, Francsen J, et al. A higher rate of serious infections in patients treated with TNF alpha blocking agents [abstract]. Arthritis Rheum 2006;54 (10 (Suppl:S365)).

33 Listing J, Strangfeld A, Kary S, et al. Infections in patients with rheumatoid arthritis treated with biologic agents. Arthritis Rheum 2005;52:3403-12.

34 Singh J, Wells $G$, Christensen $R$, et al. Adverse effects of biologics: a network meta-analysis and Cochrane overview. Cochrane Database Syst Rev 2011;(2): CD008794. doi:10.1002/14651858.CD008794.

35 The Institute for Quality and Efficiency in Healthcare (IQWiG). Rheumatoide Arthritis: Vorbericht zu Biologika in der Zweitlinientherapie erschienen. 2012. https://www. iqwig.de/ (accessed Aug 2013)

36 Klareskog L, Gaubitz M, Rodriguez-Valverde V, et al. A long-term, open-label trial of the safety and efficacy of etanercept (Enbrel) in patients with rheumatoid arthritis not treated with other disease-modifying antirheumatic drugs. Ann Rheum Dis 2006;65:1578-84.

37 Burmester GR, Mariette X, Montecucco C, et al. Adalimumab alone and in combination with disease-modifying antirheumatic drugs for the treatment of rheumatoid arthritis in clinical practice: the Research in Active Rheumatoid Arthritis (ReAct) trial. Ann Rheum Dis 2007;66:732-9.

38 Burmester GR, Panaccione R, Gordon KB, et al. Adalimumab: long-term safety in 23458 patients from global clinical trials in rheumatoid arthritis, juvenile idiopathic arthritis, ankylosing spondylitis, psoriatic arthritis, psoriasis and Crohn's disease. Ann Rheum Dis 2013;72:517-24.

39 Wolfe F, Michaud K. Biologic treatment of rheumatoid arthritis and the risk of malignancy: analyses from a large US observational study. Arthritis Rheum 2007:56:2886-95.

40 Askling J, Baecklund E, Granath F, et al. Anti-tumour necrosis factor therapy in rheumatoid arthritis and risk of malignant lymphomas: relative risks and time trends in the Swedish Biologics Register. Ann Rheum Dis 2009;68:648-53.

41 Greenberg JD, Kremer JM, Curtis JR, et al. Tumour necrosis factor antagonist use and associated risk reduction of cardiovascular events among patients with rheumatoid arthritis. Ann Rheum Dis 2011;70:576-82.

42 Westlake SL, Colebatch AN, Baird J, et al. Tumour necrosis factor antagonists and the risk of cardiovascular disease in patients with rheumatoid arthritis: a systematic literature review. Rheumatology (Oxford) 2011;50:518-31.

43 Jacobsson LTH, Turesson C, Gülfe A, et al. Treatment with tumor necrosis factor blockers is associated with a lower incidence of first cardiovascular events in patients with rheumatoid arthritis. J Rheumatol 2005;32:1213-18.

44 Carmona L, Descalzo MÁ, Perez-Pampin E, et al. All-cause and cause-specific mortality in rheumatoid arthritis are not greater than expected when treated with tumour necrosis factor antagonists. Ann Rheum Dis 2007;66:880-5.

45 Curtis JR, Xie F, Chen L, et al. The incidence of gastrointestinal perforations among rheumatoid arthritis patients. Arthritis Rheum 2011;63:346-51.

46 Rubbert-Roth A. Assessing the safety of biologic agents in patients with rheumatoid arthritis. Rheumatology (Oxford) 2012;51(Suppl. 5):v38-47.

47 Bernatsky S, Renoux C, Suissa S. Demyelinating events in rheumatoid arthritis after drug exposures. Ann Rheum Dis 2010;69:1691-3. 